\section{Teachers' Ways of Listening and Responding to Students' Emerging Mathematical Models}

\author{
Helen M. Doerr, Syracuse University
}

\begin{abstract}
In this paper, I present the results of a case study of the practices of four experienced secondary teachers as they engaged their students in the initial development of mathematical models for exponential growth. The study focuses on two related aspects of their practices: (a) when, how and to what extent they saw and interpreted students' ways of thinking about exponential functions and (b) how they responded to the students' thinking in their classroom practice. Through an analysis of the teachers' actions in the classroom, I describe the teachers' developing knowledge when using modeling tasks with secondary students. The analysis suggests that there is considerable variation in the approaches that teachers take in listening to and responding to students' emerging mathematical models. Having a welldeveloped schema for how students might approach the task enabled one teacher to press students to express, evaluate, and revise their emerging models of exponential growth. Implications for the knowledge needed to teach mathematics through modeling are discussed.
\end{abstract}

\section{ZDM-Classification: I20, M13}

More than a decade of research on teachers' professional development would suggest that, among other things, effective teachers need to attend to students' ways of thinking about mathematical tasks (Borko \& Putnam, 1996; Franke \& Kazemi, 2001; Schifter \& Fosnot, 1993; Simon \& Schifter, 1991). Understanding how students might approach a mathematical task and how their ideas might develop would seem to provide a basis for teachers to interact with students in ways that could promote student learning. However, much of the research on teachers' understandings of students' ways of thinking has focused on tasks in elementary mathematics, including important ideas in numeracy, rational numbers, and geometry (e.g., Ball, 1993; Carpenter, Fennema, Peterson, Chiang, \& Loef, 1989; Fennema, Carpenter, Franke, Levi, Jacobs, \& Empson, 1996; Jacobsen \& Lehrer, 2000). Relatively little research has been done on teachers' understanding of students' ways of thinking about tasks in areas of secondary mathematics, such as functions, algebraic equations, Euclidean geometry, and data analysis (e.g., Heid, Blume, Zbiek, \& Edwards, 1999). In addition, recent research has pointed to some of the challenges and difficulties inherent in the tasks of listening and responding to students' thinking (Chamberlin, 2003; Even \& Wallach, 2003; Morgan \& Watson, 2002; Peressini
\& Knuth, 1998; Schifter, 2001). Collectively, this research suggests a need to examine secondary teachers' ways of listening and responding to students' emerging mathematical models and the nature of the difficulties they encounter in so doing. In this paper, these issues are addressed within the context of students' engagement with a modeling task related to exponential growth.

\section{Theoretical Framework}

Recent research on the nature of teachers' knowledge has emphasized that teaching is a complex and ill-structured knowledge domain (Davis \& Simmt, 2003; Lampert, 2001). Other researchers have focused on the large extent to which knowledge is situated and grounded in the particularities of the contexts and constraints of practice (Borko, Mayfield, Marion, Flexer, \& Cumbo, 1997; Lave \& Wenger, 1991; Leinhardt, 1990). Taken together, these two perspectives suggest that understanding teachers' knowledge means understanding how teachers interpret the complexity and uncertainty of the situated practical problems of the classroom, and understanding how those interpretations influence their decisions and actions in the classroom. Expertise in complex and ill-structured domains requires the flexible use of cognitive structures to accommodate partial information, changing or unclear goals, multiple perspectives and uncertain consequences (Feltovich, Spiro, \& Coulson, 1997; Spiro, Coulson, Feltovich, \& Anderson, 1988). This implies that expertise in teaching is not a uniform, consistent or fixed set of constructs, but rather it is highly variable and needs to be understood as knowledge that develops along multiple dimensions in varying contexts for particular purposes (Doerr \& Lesh, 2003; Lesh \& Doerr, 2000). In this paper, I describe three dimensions of the knowledge needed to teach mathematics through modeling in order to illuminate teachers' ways of listening and responding to the development of students' mathematical models.

The context for this study is a model-eliciting task for exponential growth (more fully described below and in Appendix A). Model-eliciting tasks (Lesh, Hoover, Hole, Kelly, \& Post, 2000; Lesh, Cramer, Doerr, Post, \& Zawojewski, 2003) are those in which students' thought processes are explicitly revealed through the descriptions, explanations, justifications, and representations that are produced as they engage with the task and present their end products. Like other tasks which promote highlevel mathematical thinking (Henningsen \& Stein, 
1997; Stein, Grover, \& Henningsen, 1996), modeleliciting tasks provide students with opportunities to reveal how they are thinking about the situation by representing their ideas. Students' solutions will show the kinds of mathematical quantities, the relations among those quantities, and the operations and patterns that the students were thinking about. This is often referred to as the Documentation Principle (Lesh et al., 2003). Another important characteristic of model-eliciting tasks is that they are such that the students will be able to judge for themselves when their responses are good enough; this is known as the Self-Evaluation Principle. The students should not need to refer to an external authority (such as the teacher) to know when they have a satisfactory solution to the task. These task features have important implications for teachers' approaches to task implementation. Modeling tasks that are designed to engage students in high-level mathematical reasoning are more complex and more time consuming than routine mathematical tasks. These tasks are much more open to various implementation factors that could increase their complexity and the uncertainty of how events might unfold in the classroom.

Situated within the context of a model-eliciting task, this study is framed around three dimensions of teachers' knowledge: (1) an understanding of the multiple ways that students' thinking might develop, (2) ways of listening to that development and (3) ways of responding with pedagogical strategies that will support that development. The first dimension, teachers' understanding of the landscape of the development of students' ideas, has been the subject of much research (particularly at the elementary level). Knowing this landscape is not the same as understanding one particular area of the terrain (one way of thinking) or one particular pathway through the terrain (one learning trajectory). Rather, when using model-eliciting tasks, teachers are faced with the challenge of understanding the multiple ways that students might have of interpreting a problem situation and the multiple paths they might take for refining and revising their ideas. The knowledge needed for teaching includes seeing the multiple ways that students might interpret a situation and understanding that their ideas might be revised along various dimensions (while not being tested or refined along other dimensions). The teacher, in turn, needs to respond in ways that will support students' conceptual development towards more refined, more generalized, more flexible, and more integrated ways of thinking (Doerr \& Lesh, 2003; Lesh \& Doerr, 2000).

A theoretical basis for the development of students' concepts of exponential functions is provided by Confrey and Smith's (1994, 1995) descriptions of the role of multiplicative structures. These researchers have argued that the origin of the multiplicative world of the exponential function is in the actions of splitting, rather than in repeated addition. Their "splitting conjecture" suggests that seeing the constancy of successive ratios ${ }^{1}$ is as essential to an understanding of exponential functions as is the constancy of first order differences in linear functions. This assumption leads to an increased instructional emphasis on the role of tables in understanding exponential functions and for the need for students to coordinate their understanding of the additive change in the independent variable with the multiplicative change in the dependent variable as co-varying quantities (Confrey \& Doerr, 1996; Doerr, 2000). Particular examples of "splitting" include the doubling of bacteria, the half-lives of radioactive decay, tree diagrams, paper folding and geometric similarity (Confrey \& Smith, 1994, 1995). The the modeleliciting task for the students in this study is finding the closed form of a function to describe a doubling pattern of multiplicative growth. This study focuses on how the teachers see and interpret students' conceptual development as they engage with the task.

A second dimension of teachers' knowledge consists of the ways that teachers listen to the expression of student ideas. In his studies of teaching practices, Davis $(1996,1997)$ provided a framework that made three distinctions in the ways of listening that he found among the teachers. An evaluative way of listening focuses on hearing students' answers for the purpose of determining correctness. With an interpretive orientation to listening, teachers endeavor to make sense of students' responses, requiring more elaborate answers and explanations. Teachers with a hermeneutic way of listening to students' ideas engage in negotiating meaning with students and are participants who revise their own knowledge. The difficulties in listening to students with an interpretive or hermeneutic orientation are illuminated by the work of several researchers at the secondary level. In their study of teachers learning to use interviews to understand students' mathematical reasoning, Heid and colleagues (Heid et al., 1999) found that the teachers tended to use the interviews to help students arrive at correct answers, rather than to probe students' thinking. The teachers had difficulty focusing on deep understanding of students' ideas and often noted what they expected to hear. Similarly, Morgan and Watson (2002)

\footnotetext{
${ }^{1}$ This is the term used by Confrey and Smith.
} 
found that teachers tended to have difficulty in understanding and valuing student solutions that deviated from the response that the teacher was anticipating. Even and Wallach (2003) offer two perspectives on these difficulties. One perspective sees the difficulties as deficiencies or obstacles that can be overcome through experience or participation in formal professional development activities. The other perspective suggests that the intrinsic nature of hearing students is such that one "always hears through various personal factors; that it is unrealistic to expect an accurate teacher understanding of what students are saying and doing." (p. 321, emphasis in the original). How a teacher hears students is not an obstacle to be overcome, but rather hearing students is always influenced by the teacher's knowledge and understandings and the specificity of the students and the context.

When struggling with the difficulties inherent in listening to students' ways of thinking, teachers are faced with the challenge of responding in appropriate and effective ways to what they do see and interpret in students' activity. This leads to the third dimension of teacher knowledge that is relevant for this study, namely, the knowledge of pedagogical strategies that will support students' conceptual development. Current reform-based rhetoric that would exhort teachers to listen and to "not tell" does little to provide insight into what teachers could do and when and why (Chazan \& Ball, 1999), while simultaneously eroding teachers' sense of efficacy when left with little sense of a new role (Smith, 1996). Furthermore, such exhortations tend to leave the notions of listening and responding as unproblematic. In responding to the multiplicity of conceptual developments that may be taking place in her classroom, the teacher needs to choose various strategies to further that development. Such strategies could include the use of appropriate representations and the connections among those representations, a repertoire of probing questions, or insightful ways of using computational technologies. The ways in which a teacher might respond to students' mathematical activity is, of course, dependent on what it is that the teacher sees and interprets in that activity. It is precisely a teacher's perceptions and interpretations of classroom situations that influence when and why as well as what the teacher does.

The underlying conceptualization of teachers' knowledge is that of expertise that varies along the three interdependent dimensions of knowledge described above. The central questions for this study are:

- How do teachers see and interpret students' ways of thinking about exponential functions?

- How do teachers' interpretations of students' thinking influence their actions in the classroom?

To investigate these questions, I examined the practices of four experienced teachers when teaching a model-eliciting task for exponential growth.

\section{Description of the Study}

This particular case study is part of a larger research project on the development of effective pedagogical strategies for teaching modeling tasks in technology-enhanced environments. The overall project includes modeling tasks that are intended to elicit the development of students' models (or conceptual systems) of linear change, exponential growth and decay, and periodic functions. The mathematical task that the students worked on is a well-known problem in exponential growth and served as the introductory lesson for the larger unit on exponential growth and decay. The task posed to the students was to investigate the doubling pattern of pennies on a checkerboard when one penny is placed on the first square, two pennies on the second square, four on the third square, and so on. This simple recursive doubling pattern is easy for the students to see. What is considerably more difficult for the students, despite their familiarity with the algebra of exponents and exponential functions from previous coursework, is to move from a recursive view of the function to an explicit form of a function that expresses the number of pennies on each square as a function of the number of the square. The task also included an optional exploration that asked students to determine on which square the height of the pennies would reach the top of their classroom, the top of a mountain, and the distance to moon. (See Appendix for the full text of the task.)

\subsection{Participants.}

The participants in this study were four experienced secondary teachers, each of whom was teaching this particular lesson for the second time as part of a two-year project. Each teacher had 20 plus years of experience and all but one had taught precalculus for several years preceding this study. All of the teachers had strong content knowledge about exponential functions. These four teachers, along with eight others, had participated in two summer workshops where they explored the mathematics of exponential growth and decay with their colleagues and discussed various strategies that students might take in approaching this and other tasks in the 
sequence. The teachers also participated in monthly meetings during the school year in which student thinking and teaching strategies were discussed with their colleagues and the researcher. Particular attention was paid to (1) listening to and identifying the different ways students might think about a problem and (2) supporting students so that they develop and revise their own solution strategies.

These four teachers taught in three suburban public schools with middle class students. Three of the teachers taught in schools with block scheduling, where the classes met for 75 minute periods for five times over a ten day period. One of the teachers taught classes that met every day for 40 minutes. There were three female and one male teacher, but for purposes of anonymity the results are reported in a single gender. The students (ages 16 - 18 years) were mostly in grade 12 , with some grade 11 students, and were taking this course as their final high school mathematics course. Typical class size was $18-24$ students. All of the students had graphing calculators and were generally familiar with their use from previous courses in mathematics. Each of the teachers implemented the Pennies Task described above as the introduction to the overall unit on exponential growth.

\subsection{Data Sources and Analysis.}

Each of the four teachers was videotaped during the lessons in which the Pennies Task was taught. The videotaping focused on the teacher and her interactions and exchanges with the students in her class. Brief conversations with teachers following the lessons were also recorded. The videotapes were transcribed for subsequent analysis. Field notes recording the researcher's observations were taken during the lessons. The videotape of the lesson, the transcript of the videotape, and the field notes comprised the primary data sources for this study.

The data analysis was completed in two stages. The first stage of analysis involved open-ended coding (Strauss \& Corbin, 1998) of the transcripts and field notes for each teacher's lesson. This coding was revised and refined through comparing the meaning of codes across each case and within each case. This was followed by viewing the videotapes for each lesson, and adding annotations and clarifications to the transcript that were visible from the videotape. The coding of the transcript was then revised and refined in light of these annotations and clarifications.

The second stage of the analysis consisted of finding clusters of codes for each teacher that defined the critical features for each lesson. These features describe the dominant events that governed the lessons. In clustering these codes, I re-examined the data to find and interpret all those instances when the teachers were listening to and interacting with students for the purpose of understanding the students' thinking. This led to detailed descriptions of each teacher that were grounded in the data sources described above. These descriptions (and an earlier version of this paper) were shared with the teachers who confirmed the interpretations and added clarifying elaborations. After analyzing the features of the lessons for each teacher, I then compared and contrasted the findings across the teachers so as to understand the variability of the teachers' interpretations and understandings.

\section{Results}

For each teacher, I briefly describe the implementation of the lesson by that teacher and then I provide an analysis of the critical features of the lesson in order to gain insight into how the teachers were seeing and interpreting the tasks of teaching and responding to the students' ways of approaching the mathematical task.

\subsection{The Lesson in Mrs. A's Class.}

Mrs. A was the only teacher who began the Pennies Task by using actual pennies and checkerboards with her students. She was also the only teacher who assigned the Pennies Exploration Task to her students. Mrs. A allowed ample class time for the students to complete the two tasks ( 80 minutes) and neither the teacher nor the students appeared to feel overly constrained by the time available. As the students worked on the task, Mrs. A focused their attention on finding the number of pennies on the last square. After a discussion of the value of this number, the one student who had found an equation put his equation on the board, at the request of Mrs. A. The other students used this equation throughout the rest of the lesson, without having struggled with how to find it or how to express the patterns in the table. It was an explicit goal for Mrs. A to engage the students in more mathematical discussion than in the past and for her to do less talking and direct telling. Mrs. A felt that she was a good traditional teacher in that her own mathematical knowledge was sound and she was able to give good clear explanations to students. She described herself in this lesson (and other lessons in the larger unit) as "taking a risk" by moving away "from a style that is comfortable."

The analysis of the data yielded three critical features of Mrs. A’s lesson. 
(1) An awareness of differences in students' modes of sensory engagement. Mrs. A was the only teacher who engaged the students in the hands-on manipulation, counting and measurement of the pennies on the checkerboard. This is particularly striking, since some teachers and students could certainly see this type of hands-on activity as inappropriate for students of this age. But Mrs. A thought that different students needed to have different types of experiences in order to help them learn. The use of the checkerboard and pennies lasted only a few minutes into the lesson, after which most students worked on the task by completing the table. There was not any evidence as to how Mrs. A saw the hands-on experience with the pennies on the board as giving students insight into the pattern of growth.

Later in the lesson, Mrs. A described differences in "learning styles" to the students. This occurred when Mrs. A asked Jack to explain his solution for finding the number of pennies on the last square. After Jack described his solution, Mrs. A observed that most of the students in the class seem puzzled about Jack's explanation. She then turned to Jack and asked him to re-state his explanation, using the blackboard at the front of the classroom.

Student: What?

Mrs. A: I think, I mean they [the rest of the students] need a little more explanation. Makes sense. [to Jack] Do you want to use the board?

Jack: I really don't know how using the board is going to help me explain it any better.

Mrs. A: Oh, well, because some people are visual learners and when they see things on the board, it kind of helps them to follow along. See, Jack, those like you and I are auditory learners, you know. We just open our minds and that is why we never took notes. We just sat back and listened.

Mrs. A's description of herself and Jack as auditory learners and others as visual learners was a satisfactory reason for Jack, who then used the board to explain his solution. Mrs. A appeared to be aware of various approaches that students might have as auditory or visual or kinesthetic learners.

(2) Expecting that the task is recall from previous mathematics. Unlike Mrs. A's awareness of different modes of sensory engagement, I did not find similar evidence that she had an awareness of various mathematical approaches that students might use in solving the task. Indeed, she appeared to expect that the mathematics of this task would simply be a recollection of mathematics that they had been taught the previous year. In introducing the task, she commented that "some of this may be already familiar to you" and that this lesson should be "a quick little review." Soon after the students began to complete the table, Mrs. A asked them to find the number of pennies on the 64th square. It may be that Mrs. A expected that the students would see this number as $2^{63}$ and from that make a generalization to $y=2^{x-1}$. What happened was that the students focused on calculating the number of pennies on the 64th square.

Later in the lesson, when the researcher asked her how most of the students found the equation, she explained that "they were just guessing" and "they did exponentials in [last year's] course." In fact, most of the students had simply recorded Jack's solution when he gave his explanation at the board. Mrs. A expressed some regret about how the lesson had progressed: "I had hoped that they would have worked more on patterns." However, her focus in the lesson on finding the number of pennies on the 64th square appeared to have directed the students' attention on the task of calculating a specific answer rather than engaging them in a struggle with exploring patterns so as to find an equation that described the pattern.

(3) Exploring a new role for herself in listening and observing. In the linear unit, which preceded this unit, and in the previous year's lessons, Mrs. A had expressed a desire to engage her students in more mathematical discussion. This suggested that she would be doing less of the explaining in class and would engage in more careful listening to the students and allowing them to follow their own approaches. It is clear throughout the lesson that this was a new role for her. Several times in her interactions with groups of students, Mrs. A simply listened to what the students were doing. Other times, she asked them to describe what they had done and she refrained from giving them the next step or telling them what they should do.

As seen in her interaction with Jack, Mrs. A was beginning to encourage the students to give explanations to the whole class. When the students in the class appeared to not fully understand Jack's explanation, Mrs. A refrained from giving the explanation herself and continued to encourage Jack to explain his thinking. Later in the lesson, Mrs. A gave one of the students the graphing calculator connected to the overhead display unit and asked that student to explain how he had graphed the data. Both of these events indicate that Mrs. A was attempting to engage the students in expressing their ideas about the tasks at hand. In beginning the move from a teaching strategy that has been largely 
directive, Mrs. A refrained from telling students next steps as they worked in groups and encouraged individual students to give the explanations and demonstrations that she would ordinarily have given. Engaging students in expressing their own thinking was still an uncertain and emerging role for Mrs. A.

\subsection{The Lesson in Mrs. B's Class.}

Mrs. B began the lesson by asking the students to read the task and then to put themselves into groups to work on the task. The students quickly engaged with the task, created an appropriate table and entered the data into their graphing calculators. Soon after the students had done this, Mrs. B used the graphing calculator overhead unit to enter the data and display the graph and assured herself that all of the students had done this. She stated that she wanted to know what equation would fit the data, but none of the students had yet engaged with that part of the task. She directed them to work on that, commenting that "the doubling effect of the chart should give you some idea" of how to get an equation. Several students suggested different ways that they might go about finding the equation. After a brief amount of time for the students to work on this, Mrs. B wrote a chart on the board with the products of two explicitly shown on the table and a few students generated the form of the equation from that pattern. Mrs. B asked one of the students to explain why the equation worked. Using the graphing calculator overhead unit, she confirmed that the equation passed through the data points.

Three critical features emerged from the analysis of this lesson:

(1) Recognizing that students will think in various ways about the task. Immediately after Mrs. B posed the task of finding the equation, she asked for the students' ideas about how to find an equation for the data displayed on the overhead unit. She asked if the graph was a straight line, and the students clearly recognized from the display on the overhead unit that it was not, although later several students did investigate linear functions as a possible matching graph. Mrs. B asked how they might find the equation, based on the doubling pattern. Two students offered possible strategies, one based on proportions and the other using the trace function of the graphing calculator:

Mrs. B: So the doubling effect of the chart should give you some idea of <pause> what an equation might look like. Or what if I asked you without <emphasis> continuing the chart, how many pennies would there be on square 15 ? How many pennies would there be on square
30? Can you figure out how to tell me that without making a chart from one to 30 ?

Tony: Could you do, uh,

Mrs. B: Tony?

Tony: Like a proportion?

Mrs. B: I don't know. We'll see. Tony is thinking about: can we do it as a proportion?

Emma: Trace it!

Mrs. B: Well, trace what we've got on our stat plot [data lists]?

Emma: Yeah!

Mrs. B: The problem is, all we've got on our stat plot graph is what we've told it, from 1 to 6 . It [the calculator] can't go further without us telling [the calculator] any more numbers to put into the stat plot. If we can write an equation, Emma, then we can trace the equation. Correct. But we need to come up with an equation or we need to come up. <stop> Do you think Tony's idea of a proportion would work? You know. Try fiddling around with that for a minute if you want to try that. See what you think. ... Try some different things amongst yourselves here.

In responding to these students' ideas, Mrs. B kept open the possibility that using proportions might help in finding an equation and encouraged the students to work on that and other ideas that they might have. Mrs. B responded to Emma's suggestion about using the trace feature on their graphing calculators by re-stating that the crux of the question is to find an equation so that they could trace to find the values at the squares that are not part of the chart that had been entered into the calculator.

As the students continued working on the task of finding an equation, Mrs. B continued to recognize alternative approaches that students might take. Later, when a student suggested that the equation might be that of a linear function, Mrs. B said to whole class:

Mrs. B: Now, Emma asked me a question. She said, is it like 2 times something? She is on the right track, because what did we say the whole pattern was that we saw? It was doubling, which is two times something. That's good. That's something, farther than we were.

Later, when speaking with another group of students, Mrs. B reflected their thinking back to them:

Mrs. B Jack's thinking of raising two to a power.

As the students attempted to find an equation that could be used to describe the data in their table, 
Mrs. B heard their suggestions about using proportions, about the trace function on the graphing calculator, about linearity, and about raising two to a power. She responded by reflecting their thinking back to them and encouraging them to investigate the pattern in their data tables.

(2) Opening some space for the students to express their ideas. Mrs. B expected the students to have some ideas about how to find the equation that would fit the data. However, she did not give all the students adequate time to explore their ideas. As soon as a few students suggested the idea of "raising two to a power," Mrs. B wrote the following table on the board (see Figure 1).

\begin{tabular}{l|l}
\hline 1 & 1 \\
2 & 2 \\
3 & $4=2 * 2$ \\
4 & $8=2 * 2 * 2$ \\
5 & $16=2 * 2 * 2 * 2$ \\
6 & 32
\end{tabular}

Figure 1. The chart for the pennies data.

Some students quickly succeeded in finding a way to express the pattern in the table, but others did not have adequate time to engage in making their ideas explicit and in testing them. As soon as a few students came up with an equation, Mrs. B called all of the students' attention to that solution. She then used that student's solution to move the lesson along:

Mrs. B: All right, is everybody listening to Mark? He has pretty much got it.

In commenting on the student solution, she referred back to other student ideas and then emphasized the pattern of the powers of two, as she recorded Mark's solution on board:

Mrs. B: Now, we are trying to write an equation. Emma started off by saying, well, multiply by 2 which was good. Then we got the idea that this is some kind of exponent. Now, is this what you are trying to tell me, Mark? It sounded like that's what you said. [Mrs. B writes $y=2^{x-1}$ on the board.]

Mark: Sure, that's right. That's what I was trying to tell you.

Mrs. B then asked the students to confirm this equation ("Let's see how it works first of all.") by entering it on the graphing calculator connected to the overhead unit. She then returned to Mark, to ask him to explain how he came up with his solution:

Mrs. B: Mark, how did you come up with the two to the $\mathrm{x}$ minus 1 ?
Mark: Uh, I just sort of saw that it, <pause $>$

S: <inaudible comment>

Mrs. B: He was looking at ...

Mark: I was looking at the two's [on the right side of the table] and comparing it to the number at the left [side of the table]. See how there's three two's? And it's a four [on the left side of table]? So it'd be $\mathrm{x}$ minus one for that example.

Mrs. B: He was noticing these are all powers of two. And this is two to the fourth, but this is on square five. So he said that five minus one is four. And that's how you came up with it.

In re-stating Mark's solution, Mrs. B focused the students' attention on the powers of two in the table that she had written on the board earlier. She also pointed to a different row in the table (the fifth row) than what Mark had used in his argument. It is not clear from the data whether this was an intentional statement, showing that the pattern held for another row as well. It could also be that Mrs. B mis-heard Mark's explanation, as it was filtered through her own understanding of the point she was trying to make in the lesson regarding the pattern of the powers of two. As Mrs. B commented next:

Mrs. B: Now this kind of a pattern, this exponential growth pattern, is what we are going to be looking for in this whole book [unit]. We are going to be looking for exponential growth ideas, using an exponential equation to chart our growth.

The emphasis on the pattern of the powers of two and its relationship to the closed form equation was the central mathematical idea of the lesson for this teacher.

(3) Emerging in her use of the graphing calculator as a means of sense making. Mrs. B's practice had been extended in the first year of the project to include the use of the graphing calculator. In this lesson, her use of the graphing calculator began to emerge in a direction that appeared to support the sense-making activities of her students. Striking characteristics of this lesson were the ease and comfort with which Mrs. B now used the graphing calculator and the thoughtful way in which she integrated a purpose for that use that supported the students' learning.

Early in the lesson, Mrs. B encouraged all of the students to enter the data from the table into the calculator. While most of the students seemed to know how to do this, Mrs. B wanted to be sure that all of them had the necessary skills, since she knew that they would continue to use the graphing calculator in this way throughout the unit on exponential functions. Mrs. B directed the whole 
class through the details of graphing the data from the table. Later, Mrs. B confirmed that this was, in part, a way for her to re-familiarize herself with the details of using the graphing calculator. During the lesson, she was easily able to resolve a difficulty that one student had with equations that were left in the calculator from another lesson.

After publicly sharing of the graph of the data, Mrs. $\mathrm{B}$ followed her direct instruction on the skills for creating the graph with a re-focusing of the students' attention on the central mathematical task of the lesson, namely finding an equation that fits the data. As we saw earlier, after one of the students had found an equation, Mrs. B returned to the overhead unit and used the display as another way to show that the student's solution was correct, in that it fit all of the data points. When Mrs. B asked the students how they might find the number of pennies on the 64th square, she showed one strategy that she had for finding the value in the table without scrolling down the table, but then she elicited and used students' alternative approaches to finding that value, such as tracing the function and entering in the direct computation using the equation:

Mrs. B: Now, did you hear Rachael's question a minute ago? She said why don't we just substitute into this [equation] a 64. Where would we do that [on the calculator]?

In this way, Mrs. B was actively listening to how the students wanted to use their graphing calculators. She encouraged the students to use the graphing calculator in ways that made sense to them for interpreting the task and as a tool that they could use themselves to verify the match between the data and the functions.

\subsection{The Lesson in Mrs. C's Class.}

Mrs. C began the lesson by asking the students to read the task and then to think about it independently. After a few minutes she encouraged them to organize themselves into groups to work on the problem. From the outset, Mrs. C appeared to have a clear understanding that the difficulty that the students will encounter will be in finding the equation. As the lesson progressed, she repeatedly urged them to "think hard" and that what she wanted them to do was to "find the equation." Mrs. C allowed the students to engage in finding the equation for an extended amount of time. When the students had developed two different solutions to the problem, she asked both of those students to put their solutions up on the board and to explain how they arrived at their solutions. She then posed that the differences in the form of the equation were a difficulty that the students must resolve.
The analysis revealed four critical features of the teacher's ways of listening and responding in this lesson:

(1) Focusing the task and expecting student thinking. From the teacher's perspective, the central mathematical difficulty for the students was to find a closed form equation to describe the pattern of the pennies. As the students began work on the task, they generated tables and graphs on both paper and in their graphing calculators. The teacher encouraged this work, but repeatedly focused their attention on "finding the equation." Throughout the lesson, Mrs. C explicitly indicated that the problem did not have an immediate and obvious solution and that the real task for the students was to work hard and think about the task. Since this particular lesson was the first task in an extended sequence of modeling tasks, Mrs. C. wanted to make clear that the rules of the game were changing; she would not provide them with easy answers, but would give them challenging tasks that they could productively think about. Throughout the lesson, she explicitly encouraged them to "work on the hard part" and "you've got to think now. That's the hard part."

(2) Understanding students' ways of thinking about the task. Throughout the lesson, various groups of students attempted to model the exponential growth situation using linear functions, investigating the rate of change using slope, finding quadratic functions, examining the behavior of the data at the origin, and exploring the patterns of perfect squares. In all cases, the teacher listened to how the students were thinking about the task. The data revealed that the teacher was confident in her own ability to understand the diversity of students' thinking as she anticipated linear and quadratic approaches as well as listened for new approaches:

Mrs. C: Okay. And that's what I want you to do is come up with an equation. [to Sara] Are you getting anywhere with it?

Sara: Does it have anything to do with perfect squares?

Mrs. C: [repeats to self] Anything to do with perfect squares...<pause $>$ Like ... what are you looking at?

Sara: Like all the odd ones

Mrs. C: Okay <pause>

Sara: [cannot hear]

Mrs. C: Well, that's something that showed you something. Well, the even ones aren't perfect squares, though.

Mark: Yeah

Mrs. C: Well, so figure out why that might be. 
The teacher was surprised at Sara's observation of the pattern of perfect squares, and she appeared to quickly realize that every other entry in the table was a perfect square. She then reflected back to the students that not all the entries were perfect squares and encouraged them to continue thinking about why that might be so. Significantly, the students' investigation of the pattern of perfect squares and another group's investigation of the behavior of the data at the origin were novel ways of student thinking from the teacher's perspective. The teacher assimilated these approaches into her overall schema for students' ways of thinking about the task.

(3) Asking for student descriptions, explanations, and justifications. The teacher's response to the various ways of students' thinking was to ask the students to describe, explain and, on occasion, to justify their interpretations and reasoning. For example, when one student investigated slope, she asked him to describe how he found the slope and to explain how he was using that to find an equation to fit the data. In the course of the student's explanation, he recognized that "the slope is always changing." This led him to consider a quadratic function rather than a linear one.

Mrs. C: Yes. It is the slope. Didn't you do a change in y over a change in $\mathrm{x}$ ? [Bill looks on at Jerry's work]

Mrs. C [to Bill]: No, he [Jerry] did the slope correctly.

Jerry: Well is there something wrong here?

Mrs. C: No, it is the slope, right?

Bill: Okay, okay, okay, I understand what you did. All right.

Mrs. C: It is the slope of the line connecting this [point] and this [point]. But [to Jerry] what did you just say?

Jerry: the slope changes, well, yeah

Mrs. C: So in other words, if you [Jerry] used different points than he [Bill] did....

Jerry: You're going to get a different slope each time

Mrs. C: Which means?

Jerry: Then, 'cause it's not a straight line. [Mrs. C shrugs affirmatively] So this will not work.

Mrs. C: So if you used this point and this point, you won't get the same slope.

Jerry: So we have to figure out a parabola like.

In asking for descriptions and explanations, the teacher created a situation whereby the student could refine his thinking and shift to a new way of thinking about the problem. In this case, the emphasis on changing slope led Jerry to investigate whether the needed function could be quadratic.
Jerry knew from the previous unit that the slope of a parabola changes. We find it significant that Mrs. C let Jerry continue with his own way of thinking about the problem. Even though when this occurred the students had already been working on the task for a substantial amount of time, Mrs. C saw that the students were still actively engaged in pursuing a potentially viable approach to the problem. In this way, Mrs. C supported the students in evaluating their own solutions.

(4) Sharing and comparing solutions. After extended time on this task, the students had arrived at two different, but equivalent, solutions to the problem of finding an equation. The teacher made these two solutions public on the board in the front of the classroom and asked one of the two students to describe in considerable detail how he had thought about the data in order to arrive at his solution (shown in Figure 2).

$$
y=\frac{2^{x}}{2}
$$

Figure 2. Stan's equation.

Mrs. C asked Stan to stand up and speak to the class about what he had done:

Mrs. C: What were you looking at to try to find a pattern?

Stan: Um, like the relationship between like, like you know you... At first I was trying to find like how you would, if you would multiply something times $X$ to get like, to get like each number in the Y. But that didn't work out, so I then I kind of tripped upon that [the equation].

Mrs. C: Okay. Do you remember actually how you tripped upon that?

Stan: Um

Mrs. C: Because you tripped upon it first

Stan: Yeah, I was just trying to like square stuff, and then, maybe see if I could get it to come out it, and then what I did, I just... At first I went to like every other one, like every other one, you could multiply by four, you have...<trails off $>$

Mrs. C: Okay, so....

Stan: So then it just kind of gave me the, like $<$ pause $>$ that two.. All these are like, all these, you can, you know, you can square it... You can do something to the power of two and get like all these numbers.

In sharing his thinking with the class, Stan described how he first looked for a linear relationship ("multiply something times $\mathrm{X}$ to get ... each number in the $\mathrm{Y}^{\prime \prime}$ ) and then shifted to a quadratic relationship when the linear function "didn't work out." After rejecting the quadratic, Stan shifted his 
focus to the recursive pattern, only this time he realized that every other entry in his table could be found by multiplying successively by four, rather than by two. Finally, Stan recognized that "you can do something to the power of two" and this finally yielded the closed form that he was looking for.

We interpret this description by Stan as reflecting the intention of the teacher to bring the students' description of their reasoning as a part of the shared thinking of the class. In this case, Mrs. C followed Stan's comments by remarking that all of the students were looking at the chart and trying to see patterns. She engaged the whole class in an extended discussion of why the two solutions were the same and how to justify that claim.

\subsection{The Lesson in Mrs. D's Class.}

In implementing the Pennies Task, Mrs. D had time available at the end of the previous lesson and used that time to begin this task. Hence, we did not observe the initial introduction of the task and the student work on it. Thus, our findings for Mrs. D are more limited and tentative. Our observations began with the next lesson, where Mrs. D asked them to recall what they had done with the Pennies Task as a way of introducing a focus on patterns for the next task in the sequence. Mrs. D began the lesson with a re-creation of the table on the front board (which she had prepared ahead of time) and asking the students to describe what they had done. The table on the board included the entries for each square, with the number of pennies written as a product of twos, and the equation given as $y=2^{x-1}$. Mrs. D continued the lesson by asking the students to put the data table in their graphing calculator, setting an appropriate viewing window, and confirming that the equation fits the points. Mrs. D was a confident and experienced user of the graphing calculator. The students then moved on to the next task, with Mrs. D reminding them that they will need to somehow use what they have just done with the Pennies Task.

The analysis of the data yielded three critical features of Mrs. D’s lesson.

(1) Emphasizing the importance of pattern finding. For Mrs. D, the central idea in the Pennies Task was the recognition that the pattern for the number of pennies can be seen when then number of pennies on, for example, the 4th square, is written as $8=2 \cdot 2 \cdot 2=2^{3}$. Mrs. D introduced the idea that this could include a factor of 1 and be written as $8=1 \cdot 2 \cdot 2 \cdot 2=1 \cdot 2^{3}$. This anticipated the pattern that the students would see in the next task, where the lead coefficient was not 1 , but was given by some initial data in that task. However, it appeared to be an un-motivated expression from the perspective of the students. Mrs. D did not spend any time on the number of pennies on the 64th square. This suggests that she saw the focus of the task as finding the pattern and then writing the equation from the pattern.

(2) Unclear level of engagement with the central difficulty of the task. It is not clear from the data whether or not Mrs. D's students engaged with the central difficulty of the Pennies Task, namely finding a closed form equation that can be used to describe the pattern of exponential growth. As Mrs. $\mathrm{D}$ began the lesson by re-calling what had been done in the previous lesson, several students were unable to articulate what had been done, even though Mrs. D had re-created the table was on the board at the front of the room. Mrs. D asked the students to recall what they had done:

Mrs. D: As you can tell, we are going to do some group activity today and it is going to be very similar to the pennies problem that we talked about last time. So I recreated on the board what we got to last time. Okay? So take a minute, look at it and refresh your mind as to what was happening. <long pause> Jack, would you remind us what the problem was about?

Jack: No idea.

Erin: Do you have a worksheet that goes with this?

Mrs. D: Yes, but you're going to listen right now, because I'm hoping somebody would remember what it was all about.

Imad: The ones that you do times two, oh, I know that much. The one we did last time?

Mrs. D: Yeah! So tell us what it was all about.

Imad: Well, you like only double the y part. $<$ pause $>$ You just double it every time down. That is what I did last time so like. See what I mean. He [Jack] explained it last time.

Mrs. D: Okay. He took the ball over to you, so, Jack, tell us what is going on with that problem. $<$ pause $>$

Jack: The y column doubles all the way down

It would appear that Mrs. D saw the primary purpose of the task as helping the students recall familiar patterns of exponents from previous mathematics learning. In this sense, the purpose of finding the pattern and an equation was to set the stage for students engaging in the more difficult task that was to follow. However, as we saw in other teachers' lessons, finding the equation from the data table is neither easy nor obvious. Because the students described just the doubling pattern (which 
is easy for them to see), it is not clear to what extent they engaged in the central difficulty of the task, namely finding the closed form of the recursive pattern.

The lesson shifted to the use of the graphing calculator to enter the data and plot the equation. Mrs. D saw this use of the graphing calculator as reminding them about the features of the calculator, so that they would be able to use it in the next task:

Mrs. D: Now, I want to get you some practice with the TI's [graphing calculators]. So everybody take out your calculator and see if you remember how to go to the statistics key and get that [data table] into your calculator.

Several of the students encountered mis-matches with the equation. This suggests that the students did not struggle with finding the equation in the previous lesson, because, if they had, they most likely would have used their graphing calculators to test their conjectures about the equation. It would appear that many of students might not have engaged with the task at a mathematical level that would support the extension of their ideas with the next more difficult task.

(3) Engaging with the task is constrained by time. Mrs. D often commented that her students had difficulty in remembering what they had learned in previous lessons and saw her role as helping students in recalling what had been taught. Mrs. D stated that she recognized "that previous material wasn't fully understood" by her students. She saw part of her role as "encouraging students who would be easily discouraged when faced with a difficult task." It would appear that Mrs. D interpreted that the purpose of the Pennies Task was to help the students recall previous knowledge about patterns of exponents. During the lesson, she indicated that she wanted the students to recall what had been done the lesson before:

Mrs. D: So what I'm trying to get us to remember, getting you to remember, is the table. Then from the table, we can look at the pattern and from that pattern we can create an equation.

However, when the students were matching their equation to the data, several students found that their equations did not match the data. Mrs. D suggested that they check their data and how they entered the equation, but then moved the whole class on to the next problem. Mrs. D told the students who had difficulty that she would "come around and look at your calculators." She concluded this portion of the lesson by saying "so that is a quick refresher of what we did last time." The time constraints felt by Mrs. D precluded her from engaging the students collectively in resolving the mis-matches between their equations and the data. In commenting on the limited amount of time that the students spent on this task, Mrs. D explained that she felt she was "providing a tool that would allow students to come up with an equation for data." She indicated that this type of task was outside of most of her students' previous mathematical experiences.

\section{Discussion}

The differences in implementation and in the critical features of the lesson suggest that the variability in teaching is quite large. Constraints such as time and instructional goals limit what is seen in a particular lesson, leading us to be tentative in our interpretations about possible ways that the teacher might have been interpreting the events of the lesson.

First, the teachers varied in the extent to which they saw the task as an opportunity for the students to engage deeply with the mathematics of the task. In the case of Mrs. C, she clearly saw that her students should think hard about the task and that she expected them to spend time and to keep thinking even when they encountered difficulties. She was explicit in communicating this expectation to her students. Similarly, Mrs. B had an expectation that the students should think about how they might go about finding an equation, but she was quick to move the lesson along as soon as one or two students had found a solution. In contrast, two of the teachers (Mrs. A and Mrs. D) saw the task as primarily one of recall or remembering previously learned mathematics, rather than as a mathematical activity that would elicit students' thinking about multiplicative growth. It is possible that this interpretation was due in part to the familiarity of the context of this particular well-known problem.

Second, the teachers' ways of seeing and interpreting students' thinking were filtered through their own varying and developing schema for how students might think about the task. In the case of Mrs. C, she had a clear set of ideas about how students might go about making sense of the task, including exploring linear functions, investigating the rate of change using slope and finding quadratic functions. As the lesson progressed and through listening to student approaches, she added two new ideas to her schema for how students might think about the problem: examining the behavior of the data at the origin and exploring the patterns of perfect squares. Similarly, Mrs. B was aware of approaches that students might take: looking at 
proportions, finding a linear function, exploring powers of two. But Mrs. B, like Mrs. D, wanted the students to see the pattern of the powers of two and to use that to find an equation. Mrs. D saw that her main task was to make the pattern visible to students so that they would be able to use it in the subsequent task. Mrs. A appeared to have some notions about how students' learning modalities might influence their exploration of the patterns, but her focusing of the task on finding the number of pennies on the 64th square appeared to move students' thinking away from the patterns in the data towards the computation of values.

The teachers' interpretations of students' thinking influenced their actions in the classrooms in several ways. In the case of Mrs. C, having a welldeveloped schema for how students might approach the task enabled her to press her students to express, evaluate, and revise their emerging models of exponential growth. Mrs. C gave the students an extended amount of time to investigate their own ideas about the function that could be used to describe the pennies data. She asked them to explain their ideas to her and, later in the lesson, to the whole class. She encouraged them to test their ideas by comparing the graph of their equations to the graph of the data. In asking for descriptions and explanations, the teacher created a situation wherein the student himself could refine his thinking and shift to a new way of thinking about the problem.

In the case of Mrs. B, we can see that her expertise is emerging along this dimension. She clearly opened some space for her students to express their ideas about the possible patterns in the task. But for her, this lesson is better seen as supporting her continued development in using the graphing calculator to support students' learning. She used the display of the data table as an opportunity to focus the students' attention on the task of finding the equation. For her, it appeared more important that the students see the calculator as a tool for confirming their ideas than that they spend too much time in finding the equation.

It would appear that Mrs. D saw this task as preparatory for the next task, rather than as a significant mathematical investigation in its own right. The time constraints that Mrs. D experienced would further suggest that she saw this task as one to be done quickly and in a straightforward manner. In contrast to Mrs. D, Mrs. A spent an extended amount of time with this task (as much as Mrs. C). While Mrs. A seemed to think that the exploration of patterns was central to the mathematics of the task, she did not seem to have clear ideas about how the students might explore these patterns. Mrs. A's focus on how to find the number of pennies on the last square drove the lesson away from patterns (her intended direction) and towards computation. However, a better understanding of this lesson would be to see the development of her expertise in ways to engage students in more mathematical thinking and discussion. Listening to students is governed by Mrs. A's own desire to refrain from telling the students how to proceed with the task. This leaves her with a dilemma in that she has not yet established new ways of interacting with the students that are not direct telling.

\section{Implications and Conclusions}

The results of this analysis suggest that there is considerable variation in the approaches that teachers take in listening to students. At least one teacher developed a sophisticated schema for understanding the diversity of student thinking and was able to actively modify that schema as she encountered new approaches that were taken by her students. One teacher was exploring a new role for herself in listening to students' ways of thinking while refraining from the direct telling that characterized much of her practice; this listening may be a first step in developing a schema that can accommodate diversity in student thinking. Another teacher listened to the ways that students engaged with the task, but did not provide them with the extended time that they may have needed to investigate their own ideas. Yet this teacher was developing her expertise in using the graphing calculator as a tool for student exploration. Each teacher can be seen as an emerging expert along multiple dimensions of teaching expertise. These findings suggest that the variability in teaching practice reflects the complexity of the knowledge domain as well as the constraints of the particulars of the classroom setting.

Engaging students in the development of mathematical models is a shift in teaching that brings with it new demands on the role of the teacher. The essential task for the teacher is to place the students in a situation where they need to create a meaningful and useful model of some perceived phenomena for some purpose (often to explain or predict). This shifts the focus of teaching from determining what students need to be taught (as prerequisite knowledge and skills) to seeing and interpreting more deeply the knowledge that students already have. As students make visible their current ideas about a task, the teacher needs to see how those ideas can be used, built upon and extended as the students engage with the task and 
each other.

As we have seen above, students and teachers bring a great deal of diversity of thinking into the classroom. The goal for the teacher is not to classify that thinking as an end in itself, but rather to have a broad schema for ways that students might think about a task in order to provide the students with conflicts that need to be resolved or alternatives that can be tested. As teachers learn to listen to students and develop new ways of responding, we saw how some teachers began by resisting giving students the next step. Other teachers were able to place students in a situation where the students could selfevaluate their work and explore alternative approaches. When teaching mathematics through modeling, an essential task confronting the teacher as she listens to students' thinking is to respond in ways that enable students to further develop their emerging models.

\section{Acknowledgements}

This material is based upon work supported by the National Science Foundation (NSF) under Grant No. 9722235. Any opinions, findings and conclusions or recommendations expressed in this material are those of the author and do not necessarily reflect the views of the NSF.

\section{References}

Ball, D. (1993). With an eye on the mathematical horizon: Dilemmas of teaching elementary school mathematics. Elementary School Journal, 93(4), 373-97.

Borko, H., \& Putnam, R. (1996). Learning to teach. In D. Berliner \& R. Calfee (Eds.), Handbook of educational psychology (pp. 673-708). NY: Macmillan.

Borko, H., Mayfield, V., Marion, S., Flexer, R., \& Cumbo, K. (1997). Teachers' developing ideas and practices about mathematics performance assessment: Successes, stumbling blocks, and implications for professional development. Teaching and Teacher Education, 13, 259-278.

Carpenter, T. P., Fennema, E., Peterson, P. L., Chiang, C., \& Loef, M. (1989). Using knowledge of children's mathematical thinking in classroom teaching: An experimental study. American Educational Research Journal, 26, 499-532.

Chamberlin, M. (2003). Teachers investigations of students' work: Meeting the challenge of attending to students' thinking. In N. A. Pateman, B. J. Dougherty \& J. T. Zilliox (Eds.), Proceedings of the 27th Conference of the International Group for the Psychology of Mathematics Education (Vol. 2, pp 189-196). Honolulu, Hawai'i: Center for Research and Development Group, University of Hawai'i.

Chazan, D., \& Ball, D. (1999). Beyond being told not to tell. For the Learning of Mathematics, 19, 2-10.

Confrey, J., \& Doerr, H. M. (1996). Changing the curriculum to improve student understandings of function. In D. F. Treagust, R. Duit, \& B. J. Fraser (Eds.), Improving teaching and learning in science and mathematics (pp. 162-171). New York: Teachers College Press.

Confrey, J., \& Smith, E. (1994). Exponential functions, rates of change, and the multiplicative unit. Educational Studies in Mathematics, 26(2-3), 135-164.

Confrey, J., \& Smith, E. (1995). Splitting, covariation and their role in the development of exponential functions. Journal for Research in Mathematics Education, 26(1), 66-86.

Davis, B. (1996). Teaching mathematics: Toward a sound alternative. New York: Garland Publishing.

Davis, B. (1997). Listening for differences: An evolving conception of mathematics teaching. Journal for Research in Mathematics Education, 28(3), 355-76.

Davis, B., \& Simmt, E. (2003). Understanding learning systems: Mathematics education and complexity science. Journal for Research in Mathematics Education, 34(2), 137167.

Doerr, H. M. (2000). How can I find a pattern in this random data? The convergence of multiplicative and probabilistic reasoning. Journal of Mathematical Behavior, 18(4), 431454.

Doerr, H. M., \& Lesh, R. A. (2003). A modeling perspective on teacher development. In R. A. Lesh \& H. M. Doerr (Eds.), Beyond constructivism: Models and modeling perspectives on mathematics problem solving, learning and teaching (pp. 125-139). Mahwah, NJ: Lawrence Erlbaum Associates.

Even, R., \& Wallach, T. (2003). On student observation and student assessment. In L. Bragg, C. Campbell, G. Herbert \& J. Mousley (Eds.), Mathematics Education Research: Innovation, Networking, Opportunity: Proceedings of the 26th Annual Conference of the Mathematics Education Research Group of Australasia (Vol. 1, pp. 316-323). Melbourne, Australia: Deakin University.

Feltovich, P. J., Spiro, R. J., \& Coulson, R. L. (1997). Issues of expert flexibility in contexts characterized by complexity and change. In P. J. Feltovich, K. M. Ford \& R. R. Hoffman (Eds.), Expertise in context: Human and machine (pp. 125146). Cambridge, MA: AAAI/MIT Press.

Fennema, E., Carpenter, T. P., Franke, M. L., Levi, L., Jacobs, V. R., \& Empson, S. B. (1996). A longitudinal study of learning to use children's thinking in mathematics instruction. Journal for Research in Mathematics Education, 27(4), 403434.

Franke, M. L., \& Kazemi, E. (2001). Learning to teach mathematics: Focus on student thinking. Theory into Practice, 40(2), 102-109.

Heid, M. K., Blume, G. W., Zbiek, R. M., \& Edwards, B. S. (1999). Factors that influence teachers learning to do interviews to understand students' mathematical understandings. Educational Studies in Mathematics, 37, 223-249.

Henningsen, M., \& Stein, M. K. (1997). Mathematical tasks and student cognition: Classroom-based factors that support and inhibit high-level mathematical thinking and reasoning. Journal for Research in Mathematics Education, 28(5), 52449.

Lampert, M. (2001). Teaching problems and the problems of teaching. New Haven, CT: Yale University Press.

Lave, J., \& Wenger, E. (1991). Situated learning: Legitimate peripheral participation. Cambridge, England: Cambridge University Press.

Leinhardt, G. (1990). Capturing craft knowledge in teaching. Educational Researcher, 19(2), 18-25.

Lesh, R. A., Cramer, K., Doerr, H. M., Post, T., \& Zawojewski, J. S. (2003). Model development sequences. In R. A. Lesh \& H. M. Doerr (Eds.), Beyond constructivism: Models and modeling perspectives on mathematics problem solving, teaching and learning (pp 35-58). Mahwah, NJ: Lawrence Erlbaum Associates. 
Lesh, R., \& Doerr, H. M. (2000). Symbolizing, communicating, and mathematizing: Key components of models and modeling. In P. Cobb, E. Yackel \& K. McClain (Eds.), Symbolizing and communicating in mathematics classrooms: Perspectives on discourse, tools, and instructional design (pp. 361-383). Mahwah, NJ: Lawrence Erlbaum Associates.

Lesh, R., Hoover, M., Hole, B., Kelly, A., \& Post, T. (2000). Principles for developing thought-revealing activities for students and teachers. In R. A. Lesh \& A. Kelly (Eds.), Handbook of research design in mathematics and science education (pp. 591-646). Mahwah, NJ: Lawrence Erlbaum Associates.

Lesh, R. A., \& Kelly, A. E. (1999). Multi-tiered teaching experiments. In A. E. Kelly \& R. A. Lesh (Eds.), Handbook of research design in mathematics and science education (pp. 197-230). Mahwah, NJ: Lawrence Erlbaum Associates.

Jacobsen, C., \& Lehrer, R. (2000). Teacher appropriation and student learning of geometry through design. Journal for Research in Mathematics Education, 31(1), 71-88.

Morgan, C., \& Watson, A. (2002). The interpretative nature of teachers' assessment of students' mathematics: Issues for equity. Journal for Research in Mathematics Education, 33(2), 78-110.

Peressini, D. D., \& Knuth, E. J. (1998). Why are you talking when you could be listening? The role of discourse and reflection in the professional development of a secondary mathematics teacher. Teaching and Teacher Education, 14(1), 107-125.

Schifter, D. (2001). Learning to see the invisible: What skills and knowledge are needed to engage with students' mathematical ideas? In T. Wood, B. S. Nelson \& J. Warfield (Eds.), Beyond classical pedagogy: Teaching elementary school mathematics (pp. 109-134). Mahwah, NJ: Lawrence Erlbaum Associates.

Schifter, D., \& Fosnot, C. T. (1993). Reconstructing mathematics education: Stories of teachers meeting the challenges of reform. New York: Teachers College Press.

Simon, M. A., \& Schifter, D. (1991). Towards a constructivist perspective: An intervention study of mathematics teacher development. Educational Studies in Mathematics, 22, 309331.

Spiro, R. J., Coulson, R. L., Feltovich, P. J., \& Anderson, D. K. (1988). Cognitive flexibility theory: Advanced knowledge acquisition in ill-structured domains. In Tenth Annual Conference of the Cognitive Science Society (pp. 375-383). Hillsdale, NJ: Lawrence Erlbaum Associates.

Smith, J. (1996). Efficacy and teaching mathematics by telling: A challenge for reform. Journal for Research in Mathematics Education, 27(4), 387-402.

Stein, M. K., Grover, B. W., \& Henningsen, M. (1996). Building student capacity for mathematical thinking and reasoning: An analysis of mathematical tasks used in reform classrooms. American Education Research Journal, 33, 455-488.

Strauss, A., \& Corbin, J. (1998). Basics of qualitative research: Techniques and procedures for developing grounded theory (2nd ed.). Thousand Oaks, CA: Sage Publications.

\section{Author}

Helen M. Doerr, Prof.

Department of Mathematics

Syracuse University

Syracuse, NY 13244, USA

Email: hmdoerr@syr.edu

\section{Appendix}

\section{The Pennies Problem}

Fully appreciating the nature of growth and decay can help us understand much of what we see in the world around us. Many phenomena, such as the spread of the AIDS virus, radioactive decay, and the payments you make on a car, can be modeled by functions that describe how things grow or decline over time. To prepare you for investigating such phenomena, you should work on a problem that you may have seen before:

If you place a penny on the first square of a checkerboard, two pennies on the second square, four on the third square, eight on the fourth square, and so on, how many pennies are on the very last square? A checkerboard is eight by eight squares.

Fill in the following table, in which the second column gives the number of pennies on the square whose number is in the first column.

\begin{tabular}{|l|l|}
\hline $\begin{array}{l}\text { number of } \\
\text { square }\end{array}$ & $\begin{array}{l}\text { number of } \\
\text { pennies }\end{array}$ \\
\hline 1 & \\
\hline 2 & \\
\hline 3 & \\
\hline 4 & \\
\hline 5 & \\
\hline 6 & \\
\hline
\end{tabular}

Enter these values in your calculator and plot the points. What patterns do you find in the data? Write an equation that gives the number of pennies as a function of the number of the square. Graph this equation and compare it to your plot of the data points. Compare the table values of the equation with your data points. If your equation is correct, they should be the same. What is a reasonable domain and range for this function? What is the dollar value of the pennies on the 64th square?

\section{The Pennies Problem Further Explorations}

Show all work. Explain your answers.

1. On what square of the checkerboard (of infinitely many squares) will the number of pennies reach the ceiling of this room? (Height $8 \mathrm{ft}$.)

2. On what square of the checkerboard (of infinitely many squares) will the number of pennies reach the height of Mount Marcy?

3. On what square of the checkerboard (of infinitely many squares) will the number of pennies reach the moon?

4. On what square of the checkerboard (of infinitely many squares) will the number of pennies reach the sun?

5. On what square of the checkerboard (of infinitely many squares) will the number of pennies reach the sun and back? 